\title{
Factors associated with medication information in diabetes care: differences in perceptions between patients and health care professionals
}

This article was published in the following Dove Press journal:

Patient Preference and Adherence

14 October 2015

Number of times this article has been viewed

\author{
Gerda Längst' \\ Hanna Marita Seidling ${ }^{2,3}$ \\ Marion Stützle ${ }^{2,3}$ \\ Dominik Ose' \\ Ines Baudendistel' \\ Joachim Szecsenyi' \\ Michel Wensing ${ }^{1,4}$ \\ Cornelia Mahler'
}

'Department of General Practice and Health Services Research, University Hospital of Heidelberg, Heidelberg, Germany; ${ }^{2}$ Cooperation Unit Clinical Pharmacy, University of Heidelberg, Heidelberg, Germany; ${ }^{3}$ Department of Clinical Pharmacology and Pharmacoepidemiology, University of Heidelberg, Heidelberg, Germany; ${ }^{4}$ Radboud University Nijmegen Medical Centre, Scientific Institute for Quality of Healthcare, Nijmegen, the Netherlands
Correspondence: Gerda Längst

Department of General Practice and Health Services Research, University Hospital of Heidelberg, Vossstrasse 2, D-69II 5 Heidelberg, Germany

$\mathrm{Tel}+49622 I 5635559$

Fax +496221561972

Email gerda.laengst@med.uni-heidelberg.de
Purpose: This qualitative study in patients with type 2 diabetes and health care professionals (HCPs) aimed to investigate which factors they perceive to enhance or impede medication information provision in primary care. Similarities and differences in perspectives were explored.

Methods: Eight semistructured focus groups were conducted, four with type 2 diabetes patients $(n=25)$ and four with both general practitioners $(n=13)$ and health care assistants $(n=10)$. Sessions were audio and video recorded, transcribed verbatim, and subjected to computer-aided qualitative content analysis.

Results: Diabetes patients and HCPs broadly highlighted similar factors as enablers for satisfactory medication information delivery. Perceptions substantially differed regarding impeding factors. Both patients and HCPs perceived it to be essential to deliver tailored information, to have a trustful and continuous patient-provider relationship, to regularly reconcile medications, and to provide tools for medication management. However, substantial differences in perceptions related to impeding factors included the causes of inadequate information, the detail required for risk-related information, and barriers to medication reconciliation. Medication self-management was a prevalent topic among patients, whereas HCPs' focus was on fulfilling therapy and medication management responsibilities.

Conclusion: The findings suggest a noteworthy gap in perceptions between information provision and patients' needs regarding medication-related communication. Medication safety and adherence may be improved if HCPs collaborate more closely with diabetes patients in managing their medication, in particular by incorporating the patients' perspective. Health care systems need to be structured in a way that supports this process.

Keywords: medication information, patient-provider communication, type 2 diabetes, focus groups, primary care

\section{Introduction}

Suboptimal medication adherence among patients with type 2 diabetes mellitus (T2DM) has been identified, ${ }^{1-3}$ contributing to poor health outcomes and increased health care costs. ${ }^{4}$ Nonadherence is common among patients with chronic conditions. Adherence rates among seven different chronic conditions ranged from $36.8 \%$ to $80 \%$, with $65.4 \%$ of diabetes patients adhering to their medication. ${ }^{5}$ A systematic review published in 2004 found that between $36 \%$ and $93 \%$ of diabetes patients took the prescribed amount of oral hypoglycemic agents (OHA), and adherence to insulin ranged from $62 \%$ to $64 \% .{ }^{1}$ According to current evidence, these rates have changed little over the past 10 years. ${ }^{2}$ This, together with the growing incidence of T2DM patients needing medication, makes patient adherence a central part of effective diabetes management. ${ }^{6}$ 
Inadequate communication between patients and health care professionals (HCPs) has been suggested as one factor contributing to nonadherence. ${ }^{7}$ Insufficient information and a lack of medication knowledge can negatively affect patients' medication adherence. ${ }^{3,8-10}$ Research further suggested significant deficits in OHA knowledge, affecting patients as well as professionals. ${ }^{9}$

Effective communication contributes to patients' understanding of their diabetes condition as well as the benefits and risks of a prescribed medication. ${ }^{10,11}$ Adequate medication information is one important component of the informationmotivation-behavioral skills model of diabetes medication adherence and a target for interventions to promote adherence to diabetes medications. ${ }^{12}$ In Germany, general practitioners (GPs) play a central role in coordinating diabetes care, ${ }^{13}$ prescribing medications and consequently having a key role in relation to medication information processes. Improving medication information is also part of the German Health Ministry's national action plan for medication safety in Germany. ${ }^{14}$

Previous investigations regarding medication adherence have mainly focused on the medical perspective, whereas T2DM patients' perspectives have only in recent decades been taken into account. ${ }^{15,16}$ Qualitative research is needed to understand diabetes patients' experiences with medication use and the degree to which patients' information needs are reached to design a patient-tailored intervention in the primary care setting. ${ }^{15,17}$ Moreover, to reflect on current practice, the perspectives of T2DM patients, GPs, and health care assistants (HCAs; [Medizinische Fachangestellte in German]) have been incorporated. Equal consideration is seldom given to the perspectives of HCAs. HCAs, however, play an important role in general practice teams in Germany, with expanded roles in disease and care management as well as patient education. ${ }^{18}$ By comparing the different perspectives, a better understanding of the factors that hinder or facilitate the provision of medication information to T2DM patients can help general practice teams to improve medication counseling. To gain a better understanding of medication information provision in diabetes care, the perceptions of T2DM patients and HCPs delivering their care require exploration. The research reported in this paper aims to 1) investigate which factors diabetes patients and HCPs (GPs and HCAs) perceive to enhance or impede medication information provision in primary care and 2) explore similarities and differences between perspectives.

\section{Methods}

\section{Study design}

A focus group approach was adopted to explore the experiences of T2DM patients and HCPs, related to medication information in primary care. This qualitative method capitalizes on group dynamics, helping participants to explore and clarify their perspectives in ways that may not be available through individual interviews. ${ }^{19}$ Moreover, Kitzinger ${ }^{19}$ suggests that the method is particularly useful to explore not only what people think, but how they think and why they think that way.

\section{Study participants and recruitment}

Focus groups were conducted as part of a larger research project called INFOPAT (Information technologies for patient-centered healthcare, 2012-2016, http://www.infopat. eu/), aiming to assess the needs of T2DM patients and their HCPs to develop tailored information technologies and a medication communication intervention to improve medication safety and patient-provider communication.

From April to July 2013, participants were purposefully recruited with an opt-in approach from the Rhine-Neckar region in Germany. To obtain a range of experiences, German or Turkish-speaking T2DM patients (aged $\geq 18$ years) who were self-administering prescribed diabetes medications (OHA and/or insulin) were approached face-to-face through three channels: local self-help groups, GP practices, and during routine appointments at the University Hospital of Heidelberg. GPs or HCAs with diabetes expertise (selfreported knowledge and expertise about T2DM and its treatment), and experienced in caring for T2DM patients, were recruited by letter through a list of cooperating academic teaching and research practices of the Department of General Practice and Health Services Research at the University Hospital of Heidelberg. All participants willing to participate in the study completed a written informed consent form according to the Declaration of Helsinki prior to the focus group discussion. The study was approved by the local Ethics Committee of the University of Heidelberg Medical Faculty (number S-673/2012). Participants received $€ 50$ compensation for their time and travel expenses.

\section{Focus groups}

In total, eight focus groups were created with 6-8 individuals per group. Four groups were created with only T2DM patients, three groups with GPs and HCAs together, and one group with GPs only. Meetings with seven focus groups were conducted in a meeting room at the Department of General Practice and Health Services Research, while the meeting with the group of Turkish patients was conducted in Turkish at the rooms of the bilingual Turkish project partner. Each session was facilitated by two members of the research team (GL, CM, or DO) and a trained note taker who was recording 
key points and significant nonverbal behavior. Moderator and co-moderator had past focus group experience and had attended a methods workshop for group interviewing techniques. Participants completed a brief questionnaire related to sociodemographic information anonymously. Semistructured, pilot-tested interview guides (based on a literature review and developed by the interprofessional research team) alongside a moderator guide (regarding the general conduct) were used to guide the discussion on medication information provision. Following an expert review and pilot test, minor changes were made to clarify question wording and sequence of questions in the interview guides. Interview guides were matched on key themes and covered participants' experiences with medication-related information and included probes to stimulate an open discussion. The moderator summarized statements made during the discussion for validation with participants without seeking consensus. Focus groups were audio and video recorded and lasted between 110 and 130 minutes. Recruitment of new participants in the study was discontinued when no new aspects emerged in the group discussions. ${ }^{20}$

\section{Data analysis}

Audio and video recordings were transcribed verbatim with anonymity of participants completely protected. Data were analyzed using qualitative content analysis to examine patterns and themes to achieve an understanding of the meaningful content. ${ }^{21}$ Analysis proceeded in a stepwise process to structure material in codes (labels of meaning units), subcategories, and categories. ${ }^{22,23}$ Thematic categories were developed deductively based on initial theoretically driven categories from the interview guide and inductively from the text by constant comparison. Two researchers (GL, $\mathrm{CM}$ ) independently read transcripts and notes thoroughly to gain a sense of the whole and then coded half of the data to establish subcategories and categories through consensus. At first, transcripts were deductively analyzed by assigning initial categories corresponding to the themes from the interview guide. Subsequently, categories were developed inductively by identifying meaning units, condensing these into codes, and by clustering codes into subcategories based on their commonalities. Throughout the iterative process of revisiting the data and connecting them with new insights, an initial coding scheme was established including code description and definition, inclusion and exclusion criteria, and example quotes. The researcher used Atlas.ti (Version 7.0.80), a qualitative software package, to organize data and proceeded with the analysis by applying the coding scheme to the remaining transcripts. Any new content found not fitting the initial coding scheme was discussed thoroughly with the second researcher to cross check the interpretation of the data and resulted in the revision of the coding scheme. Subsequently, material pertaining to each category was analyzed to refine subcategories. Finally, subcategories and codes were examined and compared to identify similarities and differences between patients and HCPs. Researchers met regularly throughout the study to review categories and subcategories, clarify individual interpretations, and resolve any questionable coding by discussion. These consensus sessions lead to the final set of categories.

\section{Results}

A total of 48 individuals, including 25 T2DM patients, 13 GPs, and 10 HCAs, participated in 8 focus groups between May and July 2013. Demographic characteristics and recruitment of patients and professionals are displayed in Tables 1 and 2 .

T2DM patients' and HCPs' perceptions resulted in two main categories: 1) factors perceived to enhance medication information provision and 2) factors perceived to impede information provision. Similarities and differences between

Table I Characteristics of patients with type 2 diabetes who participated in the focus groups

\begin{tabular}{|c|c|}
\hline Patient characteristics & $\begin{array}{l}\text { Patient focus } \\
\text { groups }(n=25)\end{array}$ \\
\hline Sex, women, n (\%) & $7(28)$ \\
\hline Age (years), mean $\pm S D$, range & $64 \pm 8.6,49-77$ \\
\hline $\begin{array}{l}\text { Number of years diagnosed with diabetes, } \\
\text { mean } \pm S D \text {, range }\end{array}$ & $13.9 \pm 10.6,0.8-38$ \\
\hline $\begin{array}{l}\text { Number of other chronic conditions, } \\
\text { mean } \pm S D \text {, range }\end{array}$ & $3.4 \pm 1.6,1-7$ \\
\hline First language German/Turkish, n (\%) & I8 (72)/7 (28) \\
\hline \multicolumn{2}{|l|}{ Number of different medicines per day*, n (\%) } \\
\hline I-2 medicines & $2(8)$ \\
\hline 3-4 medicines & $6(24)$ \\
\hline $5-6$ medicines & $5(20)$ \\
\hline$\geq 7$ medicines & $12(48)$ \\
\hline \multicolumn{2}{|l|}{ Diabetes medication, $\mathrm{n}(\%)$} \\
\hline Oral hypoglycemic agents only & $13(52)$ \\
\hline Insulin only & $3(12)$ \\
\hline Oral hypoglycemic agents and insulin & $9(36)$ \\
\hline \multicolumn{2}{|l|}{ Education, n (\%) } \\
\hline Secondary school (9 yr) & $12(48)$ \\
\hline Secondary modern school ( 10 yr) & $5(20)$ \\
\hline Grammar school (13 yr) & $8(32)$ \\
\hline Living in partnership, $\mathrm{n}(\%)$ & $14(56)$ \\
\hline Feeling burdened, ${ }^{a}$ mean $\pm S D$, range & $4.96(2.5), 0-10$ \\
\hline \multicolumn{2}{|l|}{ Recruitment through, $\mathrm{n}(\%)$} \\
\hline Self-help groups & $15(60)$ \\
\hline University Hospital of Heidelberg & $6(24)$ \\
\hline General practitioner practices & $4(16)$ \\
\hline
\end{tabular}

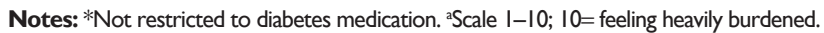
Abbreviations: SD, standard deviation; $y r$, number of years of schooling/education that the person had. 
Table 2 Characteristics of participating health care professionals

\begin{tabular}{|c|c|c|}
\hline \multirow{2}{*}{$\begin{array}{l}\text { Health care professional } \\
\text { characteristics }\end{array}$} & \multicolumn{2}{|c|}{ Professional focus groups } \\
\hline & GPs $(n=13)$ & HCAs $(n=10)$ \\
\hline Sex, women, n (\%) & $6(46.2)$ & $10(100)$ \\
\hline Age (years), mean $\pm S D$, range & $54.1 \pm 9.2,35-64$ & $38.6 \pm \mid 1.8,21-52$ \\
\hline \multicolumn{3}{|l|}{ Structure of practice, $n$ (\%) } \\
\hline Solo practice & $4(30.8)$ & $4(40)$ \\
\hline Group practice & $7(53.8)$ & $6(60)$ \\
\hline Practice sharing & I (7.7) & \\
\hline Ambulatory health center & I (7.7) & \\
\hline $\begin{array}{l}\text { Years of work experience, } \\
\text { mean } \pm S D \text {, range }\end{array}$ & $24.5 \pm 9.8,6-40$ & $15.5 \pm 12.5,0-35$ \\
\hline $\begin{array}{l}\text { Participation in DMP diabetes } \\
\text { type } 2, \mathrm{n}(\%)\end{array}$ & $13(100)$ & $10(100)$ \\
\hline \multicolumn{3}{|l|}{ Recruitment through, $\mathrm{n}(\%)$} \\
\hline Academic teaching practices & $12(92.3)$ & $8(80)$ \\
\hline Research practices & I (7.7) & $2(20)$ \\
\hline
\end{tabular}

Abbreviations: GP, general practitioner; HCA, health care assistant; SD, standard deviation; DMP, disease management program.

patients' and HCPs' perceptions are reported. For each subcategory, illustrative quotes are provided. For protection of participants' anonymity, unique identifiers (P, patient; GP, general practitioner; HCA, health care assistant; FG, focus group) are used.

\section{Factors perceived to enhance medication information provision}

This first main category (Table 3 ) includes five subcategories: 1) tailored, adequate information, 2) trusting patientprovider relationship, 3) medication reconciliation, 4) tools for medication management, and 5) a team approach to medication information. Overall, T2DM patients and HCPs had similar perceptions as to factors that would enhance medication information provision: the majority of codes were mentioned by both groups.

\section{Tailored, adequate information}

Strongest consensus among T2DM patients and HCPs was on the importance of providing tailored, adequate information. Both groups perceived that it was essential that medication information was delivered face-to-face and addressed patients' individual needs while taking their medication history and health condition into account. Providing adequate information stepwise in a proactive and timely manner in lay language was seen to contribute to patients' satisfaction with information. Alongside general information, both groups thought it was essential for T2DM patients to understand the medications' therapeutic effect on clinical parameters. One patient stated:

[...] you actually have to discuss it with the doctor, because the impact on each person is often different, and needs to be matched with your blood sugar levels and related to one personally. [P2 FG1]

Most patients knew their actual and target glycated hemoglobin $\left(\mathrm{HbA}_{1 \mathrm{c}}\right)$ values and discussed these in a lively manner.

\section{Trusting patient-provider relationship}

T2DM patients and HCPs equally viewed a trusting and continuous patient-provider relationship as a fundamental

Table 3 Factors perceived by patients and health care professionals to enhance medication information provision

\begin{tabular}{lll}
\hline Subcategory & Code & Source \\
\hline Tailored, adequate & Face-to-face and responsive communication & P, HCP \\
information & Reference to clinical parameters, overall therapy, considering health condition and life situation & P, HCP \\
& Proactive, timely provision of relevant information & P, HCP \\
& Use of lay language & P, HCP \\
& Stepwise and repeated provision & P, HCP \\
& Consideration of patients' resources and capacity & P, HCP \\
Trusting patient-provider & Trust and continuity being a necessary basis & P, HCP \\
relationship & Pivotal role of GPs in coordinating care & P HCP \\
& Responsiveness of provider & P, HCP \\
Medication reconciliation & Prerequisite to adequate information delivery & P \\
& Confidence in medication compatibility & HCP \\
Tools for medication & DMP supports medication management & HCP \\
management & Brown bag review initiated on suspicion of polypharmacy, overuse, or non-adherence, etc \\
& Medication plan adjusted to patients' needs & P, HCP \\
Team approach to & Medication plan/graphs to facilitate proper use & P, HCP \\
medication communication & Supporting patients' daily self-management & P \\
\hline
\end{tabular}

Abbreviations: $P$, perceptions of patients with type 2 diabetes; HCP, health care professionals' perceptions; GP, general practitioner; DMP, disease management program. 
condition for effective medication communication. For patients, a trusting relationship implied that HCPs were responsive to their needs, took sufficient time to discuss their concerns, and were fully informed about their medication. Patients' faith in their HCP was linked with the view that relevant information was communicated. One patient stated:

I didn't really bother about it, I somehow trust the doctor

$$
\text { [...]. [P2 FG1] }
$$

GPs were named most frequently by both groups as the primary source of medication information and were seen as having a pivotal role in care coordination.

\section{Medication reconciliation}

While both T2DM patients and HCPs stated that regular reconciliation (systematic and comprehensive review of a patient's medications to create a complete and accurate list of the current medication ${ }^{24}$ ) was a prerequisite to providing medication information, they put emphasis on different aspects. Patients described reconciliation as enhancing their confidence in their medication regime. HCPs in turn focused on medication management, and some suggested that reconciliation was facilitated by the implementation of disease management programs (DMPs). One HCA said:

[...] as part of the DMP, I think our medication communication and plans have become more solid [...]. [HCA1 FG2]

Due to time and resource constraints, however, medication reconciliation was not implemented systematically in daily practice, eg, brown bag reviews (patients bring all their medications to the HCP for comprehensive assessment) tended to be initiated by GPs when there were feelings of concern rather than being practiced as the standard.

\section{Tools for medication management}

Both groups valued tools for medication management, including medication plans, visual displays, and comprehensible labeling of medicine packages. Individualized medication plans were seen to facilitate proper use, with the majority of professionals stating that they provide plans for their patients. However, only about half of the patients participating in this study had a medication plan. For most T2DM patients, it was particularly important that tools assisted them in selfmanaging their medications. One patient described:

[...] my diabetologist. He actually made me a plan how to fine tune my insulin $[\ldots]$ told me if this leads to low blood sugar I need to [...]. [P4 FG2]
HCPs in turn emphasized that medication plans helped them to regularly review the medication regime of their chronically ill patients and to foster collaboration between professionals.

\section{Team approach to medication communication}

Primarily, HCPs discussed a team approach, which included GPs, specialists, HCAs, pharmacists, and diabetes educators to enhance medication information delivery. One GP reported about teamwork in his practice:

[...] insulin, for example, I explain how it works, what it is

$[\ldots]$ how to inject, how to prepare is done by my healthcare assistant who's also providing the [diabetes] training [...].

[GP3 FG3]

Prescribing and medication information was in the responsibility of the physician; teaching and reinforcing information was often HCAs' task. Although patients found HCAs to be more approachable than physicians, most patients perceived HCAs were not having specialist knowledge regarding their medication. HCAs also expressed a need for training in pharmacology to take on greater responsibility in providing medication-related information. For further support, physicians also referred newly diagnosed patients for diabetes education. HCPs, however, complained that insufficient collaboration and poor delineation of responsibilities in practice were an issue for them.

\section{Factors perceived to impede medication information provision}

The second main category (Table 4) also includes five subcategories: 1) inadequate information, 2) lack of/overload of information on potential adverse effects, 3) medication reconciliation impeded, 4) lack of support for medication self-management, and 5) system-related barriers. Overall, there was minimal consistency in perceptions between T2DM patients and HCPs on factors impeding medication information provision, as similar codes were scarcely found.

\section{Inadequate information}

T2DM patients and HCPs had distinct perceptions of what lead to inadequate information. Both groups identified conflicting information as being one aspect and highlighted patients' difficulties in assessing the reliability of (online) information. Beyond that, HCPs emphasized that patients' erroneous information posed challenges to the patient-provider consultation. The majority of diabetes patients, however, perceived the provision of medication information by HCPs to be insufficient. 
Table 4 Factors perceived by patients and health care professionals to impede medication information provision

\begin{tabular}{|c|c|c|}
\hline Subcategory & Code & Source \\
\hline \multirow[t]{5}{*}{ Inadequate information } & Conflicting information from different sources & $\mathrm{P}, \mathrm{HCP}$ \\
\hline & Not user-friendly, overload with certain information & $\mathrm{P}^{\mathrm{a}}$ \\
\hline & Insufficient information, dependent on discretion of provider & $\mathrm{P}^{\mathrm{a}}$ \\
\hline & Patients' forgetting information & $\mathrm{HCPa}$ \\
\hline & Family members and friends being opinion formers & $\mathrm{HCPa}$ \\
\hline Lack of/overload of information & Information not proactively provided & $\mathrm{Pa}^{\mathrm{a}}$ \\
\hline \multirow[t]{4}{*}{ on potential adverse effects } & Lack of information causes uncertainty/noncompliance & $\mathrm{P}^{\mathrm{a}}$ \\
\hline & Lack of guidance how to cope with adverse effects & $\mathrm{Pa}^{\mathrm{a}}$ \\
\hline & Detailed information creates fear/nonadherence & $\mathrm{HCP}^{\mathrm{a}}$ \\
\hline & Risks and benefits are not balanced in patient information leaflets & $\mathrm{HCP}^{\mathrm{a}}$ \\
\hline \multirow[t]{5}{*}{ Medication reconciliation impeded } & Lack of cross sectorial collaboration/full medication overview impeded & $\mathrm{P}, \mathrm{HCP}$ \\
\hline & Lack of discussion of overall medication & $\mathrm{Pa}$ \\
\hline & Time consuming & $\mathrm{HCP}$ \\
\hline & No reimbursement & $\mathrm{HCP}$ \\
\hline & Lack of patients' mutual collaboration & $\mathrm{HCPa}$ \\
\hline Lack of support for medication & Overwhelmed with insulin administration & $\mathrm{P}, \mathrm{HCP}$ \\
\hline \multirow[t]{4}{*}{ self-management } & Predetermined treatment plan not fitting daily life & $\mathrm{P}, \mathrm{HCP}$ \\
\hline & Self-management is challenging & $\mathrm{P}$ \\
\hline & Planning medication use and administration & $P$ \\
\hline & Loss of security due to medication changes & $P$ \\
\hline \multirow[t]{5}{*}{ System-related barriers } & Restricted consultation time/no reimbursement & $\mathrm{P}, \mathrm{HCP}$ \\
\hline & Drug discount contracts confuse patients & $\mathrm{P}, \mathrm{HCP}$ \\
\hline & Lack of transparency of reimbursement system & $\mathrm{P}$ \\
\hline & Drug discount contracts impose challenges on practices/black box for physicians & $\mathrm{HCP}$ \\
\hline & Deficient medication labeling & HCP \\
\hline
\end{tabular}

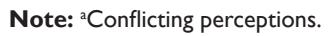

Abbreviations: $\mathrm{P}$, perceptions of patients with type 2 diabetes; $\mathrm{HCP}$, health care professionals' perceptions.

Most patients received information on dosing, but a few got as little as the recommendation "try it out" [P1 FG1].

Hence, some patients felt they were dependent on the engagement of their HCP. In addition, patients felt overloaded with certain types of information (eg, information leaflets, technical jargon), particularly if they could not find answers to specific questions or relate it to their individual situation. In contrast, HCPs reported that patients forgot information provided. A few HCPs also referred to family members and friends as being opinion formers, posing challenges to information provision.

\section{Lack of/overload of information on potential adverse effects}

Perceptions of T2DM patients and HCPs differed significantly regarding information on potential adverse effects. This topic was intensively discussed in all focus groups. Most patients perceived that they had a lack of adequate information about side effects, drug-drug interactions, and long-term effects of their prescribed medications, and the majority wished their HCPs to be more forthcoming with this information. Two patients reported experiencing episodes of hypoglycemia without much knowledge about this threatening situation and a lack of prior guidance as to how to cope with it. A few patients also described being nonadherent due to insufficient information and concerns about adverse effects. However, two patients also described not seeking information on adverse effects due to concern about its potentially negative impact. In contrast, the majority of HCPs were ambivalent toward discussing risk information in detail with patients. GPs cited the need to use their judgment when communicating this information:

[ ...] if I tell forty side effects for each medication.

[GP2 FGI] [...] nobody will take it. [GP3 FG1]

HCPs were concerned about increasing patient fear, resulting in increased nonadherence and numerous discussions. Nevertheless, HCPs believed that patients needed to be made aware of the most common side effects in order to self-monitor their medication and have strategies to minimize them. Detailed risk information provided by other sources, including the internet or pharmacists, was viewed critically.

\section{Medication reconciliation impeded}

Although a full overview of T2DM patients' current medication was viewed as being crucial to provide adequate medication 
information, both groups' perceived barriers to realize medication reconciliation in practice. The majority of HCPs named time constraints, a lack of reimbursement, and cross sectorial collaboration as significant barriers to implement medication reconciliation in practice. One GP reported:

[...] medication reconciliation with nursing homes, pharmacies, specialists, self-medication [...] doesn't work.

[GP3 FG1]

But, there were also differences in patient and HCP perceptions. Diabetes patients perceived that the discussion about the medication regime overall was lacking, particularly when medicines were changed or new ones were prescribed. HCPs in turn stated that they were reliant on patients' mutual cooperation to adequately assess a patient's medication. In addition, HCPs perceived that patients had difficulties in accurately recalling their current medications, were reluctant to tell what else they were taking, or had a different understanding what constituted a medication.

\section{Lack of support for medication self-management}

Medication self-management, defined as the range of tasks patients have to undertake to successfully manage their therapeutic regime and sustain safe medication use over time, ${ }^{25}$ was a prevalent topic among T2DM patients. Patients frequently commented on the challenges of self-managing their medications and fitting their regime into daily life. Two patients admitted to frequently forgetting to take a dose at a scheduled time and therefore took the dose later that day. Other patients mentioned that they were unsure of how to proceed if they missed a dose. A few patients reported unsatisfactory support regarding insulin administration:

[...] my doctor gave me the insulin injections and said

"inject 12 units" and that's it. No clarification that it can cause hypo's [hypoglycemia], neither how to inject, I didn't know. I did inject incorrectly the whole time at the wrong spot [...] I hurt myself [...]. [P4 FG2]

Patients' difficulties with insulin administration were also recognized by HCPs. A few patients also reported of problems with adherence to their predetermined treatment plan, as it did not fit their everyday life. Likewise, one GP also underlined that the information needed to suit the individual circumstances (eg, familial and occupational circumstances) of the patient. He described:

[...] I always write down morning, noon, evening and night

[...] I had a diabetic patient saying he injects twelve units insulin in the morning $[\ldots]$ very poor sugar $[\ldots]$ we found out he's a baker, for whom morning is actually half past midnight [...]. [GP3 FG3]

Most T2DM patients had complex medication regimes ( $\geq 5$ different types of medicines taken regularly per day), and changes were often experienced as a loss of security. It was clear from the responses of patients that some lacked strategies to accomplish the tasks to self-manage their medication on a daily basis. Moreover, medication self-management appeared to receive little attention in the patient-provider communication, as physicians seemed to focus rather on therapy and medication management responsibilities. Interestingly, however, most patients had low expectations regarding self-management support from their HCPs.

\section{System-related barriers}

T2DM patients, and particularly HCPs, repeatedly stressed that system-related barriers including time and resource constraints as well as drug discount contracts impeded the provision of medication information. One patient stated:

[...] basically there is no one who directly tells you why the medication now works $[\ldots]$ even the specialists do not have the time $[\ldots]$. [P7 FG4]

Some patients even felt uncomfortable asking for information during medical consultations. Although HCPs recognized the importance of providing adequate medication information, they felt restricted by a lack of time and resources. The negative impact of drug discount contracts was frequently discussed by patients and HCPs. For instance, when a generic alternative was dispensed, most patients expressed being confused by the changed packaging and mentioned concerns regarding adverse effects. Likewise, HCPs stressed:

\section{$[\ldots]$ that's an on-going topic $[\ldots]$ they [patients] no longer know which medication is which and take them incorrectly and a lot come to the practice reception desk and bring all their boxes with them [...]. [HCA4 FG1]}

Many HCPs reported challenges this imposed on their practice and saw it as a negative trade-off for other important aspects of their work. Furthermore, HCPs emphasized the need to improve medication labeling and appearance to facilitate understanding by patients.

\section{Discussion}

This qualitative study enabled a richer understanding and comparison of the perceptions of T2DM patients and general practice teams regarding the factors enhancing or impeding medication information provision within participants' 
broader perspectives about diabetes care and health service delivery in Germany. The disagreement points out a gap between the ideal and the real-world information delivery. Although a number of similar factors have been identified as enhancing medication information, T2DM patients and HCPs showed divergent understanding of factors impeding medication information.

For instance, perceptions considerably differed in what led to inadequate information. Patients considered medication information to be insufficient or not user-friendly due to either inadequate physician-patient communication or the manner in which information was provided. In fact, research suggests that patients with chronic conditions have a lack of information and poor understanding of medication use ${ }^{9}$ and may therefore poorly adhere with their medication regime. ${ }^{8,15}$ According to HCPs, inadequate information was either due to patients forgetting information ${ }^{26}$ or receiving unreliable information from sources other than HCPs (eg, internet, family members). Indeed, conflicting medication information may negatively influence medication adherence, and hence, a supportive physician should provide patients with reliable information sources. ${ }^{27}$

Notably, T2DM patients and HCPs had conflicting views regarding how much information on potential adverse effects should be provided. In this study and others, ${ }^{28}$ most patients wanted detailed information about adverse effects, but experienced professionals were not forthcoming with this information. Deficits in both diabetes patients' and HCPs' knowledge about relevant adverse effects of OHA have also been cited. ${ }^{9}$ In contrast, HCPs were primarily concerned that detailed information about adverse effects could increase patients' fear and thus nonadherence, ${ }^{29}$ although research suggests that informing patients about adverse effects does not negatively affect medication adherence. ${ }^{30}$ However, as a small proportion of patients did not want any information about adverse effects, it is emphasized that particularly risk information needs to be tailored to individual needs.

The lack of support for medication self-management was regarded by T2DM patients in this study as a point of particular dissatisfaction with regard to medication information and might put some patients at risk for medication-related problems. In particular, complex medication regimes and regime changes might elicit a special need for self-management support. Patients' difficulties to adhere to complex medication regimes have also previously been reported. ${ }^{31}$ Furthermore, some information and support required by T2DM patients were specifically related to insulin injection therapy (eg, dose adjustments, injection technique). Although physicians are regarded as a primary information source, this prominent issue for T2DM patients does not appear to be at the center of HCPs' attention. This might also be explained in patients "mirroring" physicians, resulting in low expectations regarding the provision of self-management support. HCPs, however, have an important role in assisting and supporting patients' medication self-management and should therefore actively seek to collaborate with patients who have problems with self-management. ${ }^{32,33}$ The findings indicate a need for HCPs to reevaluate how they provide information and self-management support, particularly related to insulin use or managing complex regimes, to their patients. Moreover, HCPs should collaborate more closely with patients to recognize their needs and apply multifaceted strategies (eg, tailored instructions, encouragement, tools supporting routine development) appropriate to patients' individual circumstances. Overall, more attention needs to be devoted to patients' self-management during all medical encounters.

Although both HCPs and T2DM patients valued medication reconciliation, structural constraints and insufficient collaboration between professionals (eg, GPs, specialists, and pharmacists) restrict the extent to which reconciliation can be achieved. Besides an interprofessional approach, patient participation has also been emphasized by HCPs as being crucial to enhance the accuracy of medication lists. ${ }^{34}$ Feedback and better education of $\mathrm{HCPs}^{35}$ and patients on the importance of medication reconciliation and a common understanding regarding what constitutes a medication are suggested to reduce medication discrepancies, improve patient satisfaction with medication-related information, and cross sectorial collaboration. ${ }^{34}$

System-related barriers were a recurring and underlying theme in both groups. While T2DM patients perceived that lack of time impeded discussions and the provision of adequate information, HCPs felt restricted in achieving their therapy and medication management responsibilities. This situation is further impeded by the impact of drug discount contracts. Previous research confirmed that changes in patients' medications due to discount contracts resulted in feelings of insecurity or confusion about medication intake. ${ }^{36}$ These circumstances impose challenges to GPs to fulfill the increased need for advice and eliminate diabetes patients' uncertainties without adequate system support. For a more cost-effective solution, appropriately trained HCAs could take on a more vital role in reviewing and communicating medication-related information. ${ }^{37}$

All in all T2DM patients and HCPs broadly highlighted the same enablers for satisfactory medication information. 
Previous research also highlighted the importance of a patient-directed communication approach to effectively deliver medication information, ${ }^{38}$ improve patient adherence, ${ }^{7}$ and foster concordance between patients and HCPs. ${ }^{39}$ A synthesis of qualitative studies concluded that information sharing requires a collaborative relationship, in which the knowledge and experiences of the individual patient are valued. ${ }^{40}$ Similar to Thom et al's ${ }^{41}$ study, T2DM patients appreciated receiving information from HCPs with whom they felt comfortable asking questions, raising concerns, and being listened to. Positive experiences made in the medical encounter increased patients' trust in their HCP. In fact, evidence suggests that patient trust is related to treatment adherence. Moreover, the current study supports the critical role of a structured and collaborative approach to medication reconciliation to maximize the quality and safety of care. Diabetes patients viewed medication reconciliation as enhancing their confidence in their medication regime, whereas HCPs viewed it as an important component of their medication management. Tools for medication management were also seen to benefit patients and HCPs alike by increasing patients' participation, fostering self-management, ${ }^{4}$ and assisting reconciling medicines across the care continuum. ${ }^{34}$ Thus, it is essential that every patient possesses a complete and accurate medication list. Similar to HCPs perceptions in this study, research suggests that adequate medication communication requires a collaborative approach and clear delineation of responsibilities. ${ }^{29}$ Although GPs were viewed as the primary information source, improving the cooperation with other members of the health care team (eg, pharmacists, HCAs, diabetes educators, nurses) is necessary to fulfill all patients' information needs. Moreover, patients in particular do not seem to be aware of which information to expect from different HCPs. For instance, pharmacists have the expertise to initiate counseling (eg, application, side effects) and medication reconciliation activities to ensure safe and appropriate medication use, but they are currently an underutilized resource.

The implementation of a structured medication management intervention (eg, medication reconciliation, computerassisted medication check, medication list) into existing practice structures (eg, DMP counseling) ${ }^{42}$ can support patients in their self-management while enhancing HCP's medication management.

One of the strengths of this study is that the perspectives of T2DM patients, GPs, and HCAs were incorporated. Participants, however, may have a greater interest in medication communication and may represent the perspectives of more adherent patients or supportive HCPs. Consequently, we do not know the perspective of potential participants who chose not to participate. Moreover, this study did not specifically focus on low-literate, low-adherent T2DM patients, their caregivers, or other HCP groups. Incorporating their experiences may have generated a fuller picture of the situation. While multiple coding is recommended throughout the process to increase reliability, only half of the entire dataset was coded independently by two researchers for pragmatic reasons. This was considered justifiable as the coding scheme only needed slight adaptation. To compensate this weakness, the researchers thoroughly discussed any new content or disagreement found with the initial coding scheme to reach consensus on the final set of categories. Despite the limitations, our study provides important information on factors which may explain some of the current challenges in the provision of medication information.

\section{Conclusion}

The findings identify a gap in perceptions between what information is provided to T2DM patients and what is wanted from patients during medication-related communication. These differences in perceptions relate to the adequacy of medication and risk information with patients, placing emphasis on assistance with medication self-management, whereas HCPs are concerned about their therapy and medication management responsibilities. The current gap in medication communication expectations may give the impression that it is of little importance in diabetes management. However, medication information needs a firm place in the patient-provider consultation and should also play a central role in professional training and cross sectorial collaboration. Optimal medication information may be achievable if HCPs collaborate more closely with patients in managing diabetes medication and if health care systems support this process to achieve favorable outcomes. Moreover, it is clear that patients' perspective on medication information should be incorporated in the patient-provider consultation. Accordingly, a first step in communicating with T2DM patients about their medication is recognizing needs, beliefs, and values they hold.

\section{Acknowledgments}

This article presents independent research supported by grants from the German Federal Ministry of Education and Research (BMBF, funding code 01KQ1003B). We thank all study participants for sharing their perspectives and experiences in the course of this study. We also thank Christina 
Reiß and Dr Gökçe Karakas (Selbsthilfe Heidelberg/ Mannheim), as well as physicians and health care workers in the Rhine-Neckar region for their assistance with recruitment and data collection. We further thank Sarah Berger, an English native speaker working at the Department of General Practice and Health Services Research, for reviewing this manuscript.

\section{Disclosure}

The authors report no conflicts of interest in this work.

\section{References}

1. Cramer JA. A systematic review of adherence with medications for diabetes. Diabetes Care. 2004;27(5):1218-1224.

2. Krass I, Schieback P, Dhippayom T. Adherence to diabetes medication: a systematic review. Diabet Med. 2014;32(6):725-737.

3. Ahmad NS, Ramli A, Islahudin F, Paraidathathu T. Medication adherence in patients with type 2 diabetes mellitus treated at primary health clinics in Malaysia. Patient Prefer Adherence. 2013;7:525-530.

4. Bosworth HB, Granger BB, Mendys P, et al. Medication adherence: a call for action. Am Heart J. 2011;162(3):412-424.

5. Briesacher BA, Andrade SE, Fouayzi H, Chan KA. Comparison of drug adherence rates among patients with seven different medical conditions. Pharmacotherapy. 2008;28(4):437-443.

6. Rhee MK, Slocum W, Ziemer DC, et al. Patient adherence improves glycemic control. Diabetes Educ. 2005;31(2):240-250.

7. Haskard Zolnierek KB, DiMatteo MR. Physician communication and patient adherence to treatment: a meta-analysis. Med Care. 2009; 47(8):826-834.

8. Gordon K, Smith F, Dhillon S. Effective chronic disease management: patients' perspectives on medication-related problems. Patient Educ Couns. 2007;65(3):407-415.

9. Browne DL, Avery L, Turner BC, Kerr D, Cavan DA. What do patients with diabetes know about their tablets? Diabet Med. 2000;17(7): $528-531$.

10. Rubin RR. Adherence to pharmacologic therapy in patients with type 2 diabetes mellitus. Am J Med. 2005;118(Suppl 5A):S27-S34.

11. Osterberg L, Blaschke T. Adherence to medication. $N$ Engl J Med. 2005;353(5):487-497.

12. Mayberry LS, Osborn CY. Empirical validation of the informationmotivation-behavioral skills model of diabetes medication adherence: a framework for intervention. Diabetes Care. 2014;37(5): $1246-1253$.

13. Szecsenyi J, Rosemann T, Joos S, Peters-Klimm F, Miksch A. German diabetes disease management programs are appropriate for restructuring care according to the chronic care model: an evaluation with the patient assessment of chronic illness care instrument. Diabetes Care. 2008;31(6):1150-1154.

14. German Ministry of Health. Aktionsplan 2013-2015 des Bundesministeriums für Gesundheit zur Verbesserung der Arzneimitteltherapiesicherheit in Deutschland [National action plan 20132015 for drug safety in Germany]. Available from: http://www.akdae. de/AMTS/Aktionsplan/Aktionsplan-AMTS-2013-2015.pdf. Accessed January 3, 2015. German.

15. Vermeire E, Hearnshaw H, Van Royen P, Denekens J. Patient adherence to treatment: three decades of research. A comprehensive review. J Clin Pharm Ther. 2001;26(5):331-342.

16. Al Hamid A, Ghaleb M, Aljadhey H, Aslanpour Z. A systematic review of qualitative research on the contributory factors leading to medicine-related problems from the perspectives of adult patients with cardiovascular diseases and diabetes mellitus. BMJ Open. 2014;4 (9):e005992.
17. Elwyn G, Edwards A, Britten N. What information do patients need about medicines? "Doing prescribing": how doctors can be more effective. BMJ. 2003;327(7419):864-867.

18. Freund T, Everett C, Griffiths P, Hudon C, Naccarella L, Laurant M. Skill mix, roles and remuneration in the primary care workforce: who are the healthcare professionals in the primary care teams across the world? Int J Nurs Stud. 2015;52(3):727-743.

19. Kitzinger J. Qualitative research: introducing focus groups. BMJ. 1995; 311(7000):299-302.

20. Bowen GA. Naturalistic inquiry and the saturation concept: a research note. Qual Res. 2008;8(1):137-152.

21. Krippendorff K. Content Analysis. An Introduction to its Methodology. The Sage Commtext Series. 2nd ed. Thousand Oaks, CA: Sage Publications Ltd.; 2004.

22. Mayring P. Qualitative Inhaltsanalyse. Grundlagen und Techniken [Qualitative content analysis. Principles and techniques]. 11th ed. Weinheim \& Basel: Beltz Verlag; 2010. German.

23. Kuckartz U. Qualitative Inhaltsanalyse. Methoden, Praxis, Computerunterstützung [Qualitative Text Analysis. Methods, Practice, Using Software]. Weinheim \& Basel: Beltz Juventa; 2012. German.

24. Greenwald JL, Halasyamani L, Greene J, et al. Making inpatient medication reconciliation patient centered, clinically relevant and implementable: a consensus statement on key principles and necessary first steps. J Hosp Med. 2010;5(8):477-485.

25. Bailey SC, Oramasionwu CU, Wolf MS. Rethinking adherence: a health literacy-informed model of medication self-management. $J$ Health Commun. 2013;18(Suppl):20-30.

26. Aikens JE, Piette JD. Longitudinal association between medication adherence and glycaemic control in Type 2 diabetes. Diabet Med. 2013; 30(3):338-344.

27. Carpenter DM, DeVellis RF, Fisher EB, DeVellis BM, Hogan SL, Jordan JM. The effect of conflicting medication information and physician support on medication adherence for chronically ill patients. Patient Educ Couns. 2010;81(2):169-176.

28. Ziegler DK, Mosier MC, Buenaver M, Okuyemi K. How much information about adverse effects of medication do patients want from physicians? Arch Intern Med. 2001;161(5):706-713.

29. Tarn DM, Paterniti DA, Williams BR, Cipri CS, Wenger NS. Which providers should communicate which critical information about a new medication? Patient, pharmacist, and physician perspectives. J Am Geriatr Soc. 2009;57(3):462-469.

30. Lamb GC, Green SS, Heron J. Can physicians warn patients of potential side effects without fear of causing those side effects? Arch Intern Med. 1994;154(23):2753-2756.

31. Donnan PT, MacDonald TM, Morris AD. Adherence to prescribed oral hypoglycaemic medication in a population of patients with type 2 diabetes: a retrospective cohort study. Diabet Med. 2002;19(4): 279-284.

32. Ahola AJ, Groop PH. Barriers to self-management of diabetes. Diabet Med. 2013;30(4):413-420.

33. Guénette L, Lauzier S, Guillaumie L, Giguère G, Grégoire J-P, Moisan J. Patients' beliefs about adherence to oral antidiabetic treatment: a qualitative study. Patient Prefer Adherence. 2015;9:413-420.

34. Nassaralla CL, Naessens JM, Chaudhry R, Hansen MA, Scheitel SM. Implementation of a medication reconciliation process in an ambulatory internal medicine clinic. Qual Saf Health Care. 2007;16(2): 90-94.

35. Mahler C, Hermann K, Jank S, Haefeli WE, Szecsenyi J. Can a feedback report and training session on medication counseling for general practitioners improve patient satisfaction with information on medicines? Patient Prefer Adherence. 2012;6:179-186.

36. Leutgeb R, Mahler C, Laux G, Weschnetz A, Szecsenyi J. Krankenkassen-Rabattverträge: Probleme und Risiken für den Hausarzt bei der Betreuung chronisch kranker Patienten [Health insurance discount contracts: problems and risks for the general practitioner in the medical care of patients with chronic illness]. Dtsch Med Wochenschr. 2009;134(5):181-186. German. 
37. Zullig LL, Gellad WF, Moaddeb J, et al. Improving diabetes medication adherence: successful, scalable interventions. Patient Prefer Adherence. 2015;9:139-149.

38. McGrath JM. Physicians' perspectives on communicating prescription drug information. Qual Health Res. 1999;9(6):731-745.

39. Ose D, Mahler C, Vogel I, Ludt S, Szecsenyi J, Freund T. Let's talk about medication: concordance in rating medication adherence among multimorbid patients and their general practitioners. Patient Prefer Adherence. 2012;6:839-845.

40. Paterson BL, Thorne S, Dewis M. Adapting to and managing diabetes. Image J Nurs Sch. 1998;30(1):57-62.
41. Thom DH, Hall MA, Pawlson LG. Measuring patients' trust in physicians when assessing quality of care. Health Aff (Millwood). 2004; 23(4):124-132.

42. Mahler C, Freund T, Baldauf A, et al. Das strukturierte Medikamentenmanagement in der Hausarztpraxis - ein Beitrag zur Förderung der Arzneimitteltherapiesicherheit [Structured medication management in primary care - a tool to promote medication safety]. Z Evid Fortbild Qual Gesundhwes. 2014;108:258-269. German.

\section{Publish your work in this journal}

Patient Preference and Adherence is an international, peer-reviewed, open access journal that focuses on the growing importance of patient preference and adherence throughout the therapeutic continuum. Patient satisfaction, acceptability, quality of life, compliance, persistence and their role in developing new therapeutic modalities and compounds to optimize clinical outcomes for existing disease states are major areas of interest for the journal. This journal has been accepted for indexing on PubMed Central. The manuscript management system is completely online and includes a very quick and fair peer-review system, which is all easy to use. Visit http://www. dovepress.com/testimonials.php to read real quotes from published authors.

\footnotetext{
Submit your manuscript here: http://www.dovepress.com/patient-preference-and-adherence-journal
} 